\title{
Resetting of the luminescence signal in modern riverbed cobbles along the course of the Shiyang River, China
}

Liu, Jinfeng; Cui, Furong; Murray, Andrew Sean; Sohbati, Reza; Jain, Mayank; Gao, Hongshan; Li, Wenpeng; Li, Chaopeng; Li, Ping; Zhou, Tiangui

Total number of authors:

11

Published in:

Quaternary Geochronology

Link to article, DOI:

10.1016/j.quageo.2018.04.004

Publication date:

2019

Document Version

Peer reviewed version

Link back to DTU Orbit

Citation (APA):

Liu, J., Cui, F., Murray, A. S., Sohbati, R., Jain, M., Gao, H., Li, W., Li, C., Li, P., Zhou, T., \& Chen, J. (2019). Resetting of the luminescence signal in modern riverbed cobbles along the course of the Shiyang River, China. Quaternary Geochronology, 49, 184-190. https://doi.org/10.1016/j.quageo.2018.04.004

\section{General rights}

Copyright and moral rights for the publications made accessible in the public portal are retained by the authors and/or other copyright owners and it is a condition of accessing publications that users recognise and abide by the legal requirements associated with these rights.

- Users may download and print one copy of any publication from the public portal for the purpose of private study or research.

- You may not further distribute the material or use it for any profit-making activity or commercial gain

- You may freely distribute the URL identifying the publication in the public portal 


\section{Accepted Manuscript}

Resetting of the luminescence signal in modern riverbed cobbles along the course of the Shiyang River, China

Jinfeng Liu, Furong Cui, Andrew S. Murray, Reza Sohbati, Mayank Jain, Hongshan Gao, Wenpeng Li, Chaopeng Li, Ping Li, Tiangui Zhou, Jie Chen

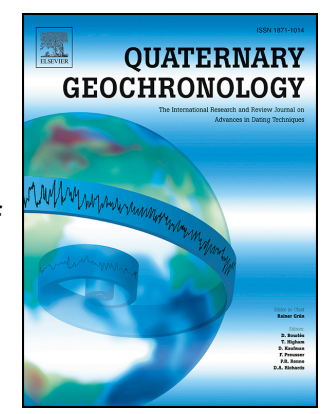

PII:

S1871-1014(17)30229-7

DOI:

10.1016/j.quageo.2018.04.004

Reference: QUAGEO 915

To appear in: Quaternary Geochronology

Received Date: 6 December 2017

Revised Date: 6 April 2018

Accepted Date: 11 April 2018

Please cite this article as: Liu, J., Cui, F., Murray, A.S., Sohbati, R., Jain, M., Gao, H., Li, W., Li, C., Li, P., Zhou, T., Chen, J., Resetting of the luminescence signal in modern riverbed cobbles along the course of the Shiyang River, China, Quaternary Geochronology (2018), doi: 10.1016/ j.quageo.2018.04.004.

This is a PDF file of an unedited manuscript that has been accepted for publication. As a service to our customers we are providing this early version of the manuscript. The manuscript will undergo copyediting, typesetting, and review of the resulting proof before it is published in its final form. Please note that during the production process errors may be discovered which could affect the content, and all legal disclaimers that apply to the journal pertain. 
Resetting of the luminescence signal in modern riverbed cobbles along the course of the Shiyang River, China

Jinfeng Liu ${ }^{1 *}$, Furong Cui ${ }^{1,2}$, Andrew S. Murray ${ }^{3}$, Reza Sohbati ${ }^{3,4}$, Mayank Jain ${ }^{4}$,

${ }^{1}$ State Key Laboratory of Earthquake Dynamics, Institute of Geology, China Earthquake Administration, Beijing 100029, China

${ }^{2}$ School of Earth Sciences and Resources, China University of Geosciences, Beijing 100083, China

${ }^{3}$ Nordic Laboratory for Luminescence Dating, Department of Geoscience, University of Aarhus, DTU Risф campus, DK-4000, Roskilde, Denmark ${ }^{4}$ Centre for Nuclear Technologies, Technical University of Denmark, DTU Ris $\phi$ campus, DK-4000, Roskilde, Denmark ${ }^{5}$ Key Laboratory of Western China's Environmental Systems (Ministry of Education), College of Earth and Environmental Sciences, Lanzhou University, Lanzhou 730000, China 
Luminescence dating can potentially be applied to determine the burial ages of rock surfaces. As part of testing the reliability and applicability of this technique, we sampled a series of modern riverbed cobbles along the Shiyang River, which occupies an endorheic basin in northwest China. The infrared stimulated luminescence (IRSL) signal was measured as a function of depth for cobbles of two different lithologies (sandstone and granite). The results show that (i) the bleaching rate of the signal for light-coloured granite is higher than for opaque dark-coloured sandstone, because granite is bleached to greater depths than sandstone; (ii) cobble daylight bleaching depths show a downstream increasing trend, with almost all bleaching occurring in the upstream section; and (iii) despite possible abrasion of the upper surface of granite cobbles, the bleaching depth in the upper surface is greater than in the lower surface, indicating longer exposure times for the upper faces of cobbles. This work has important implications for the age-dating of fluvial deposits and the potential application of luminescence techniques to understand transport and deposition in fluvial environments.

Keywords: luminescence; rock surface; modern riverbed cobbles; bleaching

\section{Introduction}

When a rock surface is exposed to daylight, the resetting of the luminescence signal progresses deeper into the surface with time (Liritzis and Galloway, 1999; Habermann et al., 2000; Polikreti et al., 2002; Vafiadou et al., 2007; Laskaris and Lirtizis, 2011; Sohbati et al., 2011, 2012a, b). Upon burial, the rock surface is no longer exposed to daylight and the accumulation of trapped electrons takes place until exhumation (Liritzis et al., 1997; Sohbati et al., 2012c). The effect of this resetting and accumulation is recorded in the luminescence-depth profile beneath the rock surface, as long as it is not overwritten by subsequent more prolonged burial/exposure 
events (Chapot et al., 2012; Sohbati et al., 2012c, 2015; Freiesleben et al., 2015). Thus, by measuring the luminescence signal with depth within a rock surface, sequential phases of daylight exposure and burial can be detected (Sohbati et al., 2012c, 2015; Freiesleben et al., 2015). This technique provides a unique tool to test assumptions about the surface exposure history prior to final emplacement of an individual rock sample and offers a direct method for determining the time elapsed since the last burial (i.e. the burial age). This requires measurement of the dose recorded in rock slices from the surface to several millimeters depth (Sohbati et al., 2012c, 2015; Freiesleben et al., 2015).

Employing basic principles similar to sediment age-dating (Aitken, 1985), a critical requirement for successful measurement of the burial age of rock surfaces is that a sufficiently thick surficial layer was reset to a near-zero level of luminescence before burial (Liritzis et al., 1996). Laboratory bleaching experiments using optically stimulated luminescence (OSL) or infrared stimulated luminescence (IRSL) (e.g. Habermann et al., 2000; Vafiadou et al., 2007) and measurements on modern beach cobbles and boulders (Sohbati et al., 2011) have shown that rock surfaces can be sufficiently bleached when exposed to a few hours of daylight (or a solar simulator). However, few systematic studies exist on the resetting of the luminescence signal in modern rock samples in a dynamic river transport system, where processes such as abrasion and sorting may be important.

Here we report on an investigation of daylight bleaching in modern riverbed cobbles with contrasting lithologies, and on opposite sides of cobbles, along a river course. Such basic work serves two purposes: (i) it adds new data on the behaviour of the zeroing of IRSL signals in different rock types and the variability within a single cobble, and (ii) it provides information to guide a suitable sampling strategy for dating the burial age of rocks. Overall, this work contributes towards improving the accuracy of dating the time of burial of a rock surface. 


\section{Study areas and sampling}

The endorheic Shiyang River flows from the North Qilian Mountains on the northeast margin of the Tibetan Plateau to the Tengger Desert (Fig. 1). The river has eight major tributaries and several minor tributaries. These flow north-eastwards out of the mountains and converge to form the main Shiyang River in the lower reaches near the city of Wuwei. Runoff within the drainage basin is supplied mainly by precipitation, with glacial meltwater from the North Qilian Mountains contributing only 7\% (Ding and Wang, 2001). In total, 12 sampling sites were visited along the Xiying River, one of the longest branches of the Shiyang River. Elevation along the river profile decreases from $\sim 3500 \mathrm{~m}$ above sea level (a.s.1) to $\sim 1500 \mathrm{~m}$ a.s.1 (Fig. 2). Only samples from three sites (I, II, and III) (Fig. 2 and Fig. S1) are employed in this preliminary study. Sampling sites I and II are located in mountain valleys and site III on the alluvial plain (Fig. 2). The width of the river bed increases from site I to site III. Following the downstream fining law attributed to abrasion, hydraulic sorting, and weathering processes (Knighton, 1998), the average clast size in the riverbed decreases progressively from boulder size $(\mathrm{b}$-axis $>25 \mathrm{~cm})$ to cobble size $(>6 \mathrm{~cm})$ with distance downstream from the river source to the last sampling site (here, $\sim 120$ km; Fig. 2 and Fig. S1).

Sandstone and granite cobbles, with diameters between 8 and $25 \mathrm{~cm}$, were selected at each site (Table 1). The upper side of each sample was marked before being wrapped in opaque aluminium foil and sealed with adhesive tape.

\section{Methods}

The cobble samples were prepared at the Institute of Geology of the China Earthquake Administration (IoG CEA), Beijing, China. Under subdued red-orange light, cores of $\sim 10 \mathrm{~mm}$ in diameter and up to $30-40 \mathrm{~mm}$ long were drilled into the rock surface using a water-cooled diamond drill. For some fragile granite cobbles, cuboids with cross sections of $7 \times 7 \mathrm{~mm}$ were cut using a water-cooled saw. These 
cuboid samples were then sliced into $\sim 0.7 \mathrm{~mm}$ slices using a water-cooled low-speed saw equipped with a $0.3 \mathrm{~mm}$ diamond wafer blade, giving a net slice spacing of 1.0 $\mathrm{mm}$.

Luminescence measurements were carried out at the IoG CEA using a Ris $\varnothing$ TL/OSL reader (model DA-20) with infrared light stimulation $(870 \mathrm{~nm}, \sim 130$ $\mathrm{mW} / \mathrm{cm}^{2}$ ) and photon detection through a Schott BG 39/Corning 7-59 blue filter combination ( 2 and $4 \mathrm{~mm}$, respectively). Beta irradiations used a calibrated ${ }^{90} \mathrm{Sr} /{ }^{90} \mathrm{Y}$ source mounted on the reader (Bøtter-Jensen et al., 2010).

Luminescence dating techniques have been developed mainly for separated quartz and feldspar target minerals. However, it is difficult to separate pure mineral phases in igneous rock slices without losing grain-size-dependent dosimetric information. Several studies have shown that the infrared stimulated luminescence (IRSL) signal in blue emission band from coarse grains is probably associated mainly with K-rich feldspar (e.g. Baril and Huntley, 2003; Zhao and Li, 2005; Sohbati et al., 2013). As a result, we adopted a conventional IRSL single-aliquot regenerative-dose (SAR) protocol (Wallinga et al., 2000) to measure the solid rock slices. The natural IRSL signal $\left(\mathrm{L}_{n}\right)$, and the subsequent response to a test dose $\left(\mathrm{T}_{\mathrm{n}}\right)$ from each slice, were measured using the IRSL signal at $50^{\circ} \mathrm{C}\left(\mathrm{IR}_{50}\right)$ for $100 \mathrm{~s}$. A pause of $30 \mathrm{~s}$ was introduced before the stimulation to reduce thermal lag; i.e. to ensure that all the grains within a slice reached the stimulation temperature prior to optical stimulation (Jain et al., 2007). The same thermal pretreatment of $250^{\circ} \mathrm{C}$ for $100 \mathrm{~s}$ was applied before the natural and test doses. At the end of each SAR cycle, an IR stimulation at $290^{\circ} \mathrm{C}$ for $100 \mathrm{~s}$ was employed to minimize recuperation (Buylaert et al., 2007; Wallinga et al., 2007).

\section{Results}

\subsection{Characteristics of the luminescence signal}

Fig. 3 shows the IRSL curves from the natural dose and the laboratory 
dose-response curves (Fig. 3 inset; $L_{n} / T_{n}$ ) for the deepest-cored slices in sandstone and granite cobbles. All other samples give a strong IRSL signal similar to those shown in Fig. 3. The laboratory dose-response curves can be well represented by the sum of two saturating exponential functions. The curves pass close to the origin and the recycling ratio is close to unity for all the slices, indicating that laboratory doses given after heating can be reproducibly measured using the SAR protocol. In addition, the full dose-response curves show that the natural IRSL signal from these deep, presumably unbleached slices lies below the laboratory saturation limit, consistent with a field equilibrium that likely arises from trap filling and anomalous fading. The ratio of the sensitivity-corrected natural IRSL signal $\left(\mathrm{L}_{\mathrm{n}} / \mathrm{T}_{\mathrm{n}}\right)$ from such deep slices to the laboratory saturation level $\left(\mathrm{L}_{\mathrm{sat}} / \mathrm{T}_{\text {sat }}\right.$; amplitude of the saturating exponential curve fit to the dose-response data) was $\sim 0.85$ for the sandstone sample (Fig. $3 \mathrm{~A}$ ) and $\sim 0.60$ for the granite sample (Fig. 3B).

\subsection{Variations in luminescence resetting along the river course}

Fig. 4 shows changes in the normalized sensitivity-corrected natural IRSL signal $\left(\mathrm{L}_{\mathrm{n}} / \mathrm{T}_{\mathrm{n}}\right)$ with depth in the sandstone (Fig. 4A) and granite (Fig. 4B) cobbles from sites I to III. Values are normalized to the average $\mathrm{L}_{\mathrm{n}} / \mathrm{T}_{\mathrm{n}}$ values, at saturation depths of $>4$ and $>15 \mathrm{~mm}$ for the sandstone and granite cobbles, respectively. All cobbles have similar diameters ranging from $\sim 10$ to $22 \mathrm{~mm}$ (Table 1). For sandstone cobbles, saturation begins below $\sim 3 \mathrm{~mm}$ depth, and only the first one or two slices $(0-1 \mathrm{~mm}$ depth) have a $\mathrm{L}_{\mathrm{n}} / \mathrm{T}_{\mathrm{n}}$ ratio less than $10 \%$ of the saturation level. For granite cobbles, the luminescence is near zero down to a depth of $\sim 5 \mathrm{~mm}$ for site $\mathrm{I}$, and is near zero down to $\sim 7 \mathrm{~mm}$ for sites II and III. These depths are therefore defined as the resetting depths. The signal then begins to increase gradually until it reaches saturation at a depth of $\sim 15 \mathrm{~mm}$. This depth is defined as the saturation depth. It appears that, for these samples, the resetting and saturation depths are greater in granite cobbles than in sandstone cobbles.

Along the river, for both sandstone and granite lithologies, the fitted signal-depth 
bleaching profiles of cobbles from site I upstream are closer to the rock surface than the profiles in cobbles from sites II and III farther downstream. Upstream cobbles must therefore have been exposed to less light. Any possible effects of attrition and abrasion on cobbles through downstream transport would only tend to reduce these effects. Longer light exposure in downstream cobbles can therefore be considered as indicative of their longer transport history. The profiles of cobbles from sites II and III are indistinguishable, suggesting that they have similar transport (light exposure) histories.

Fig. 5A shows the depth of the inflection point (in these cases, the depth at which the signal intensity is $\sim 50 \%$ of that in saturation) versus the transport distance for granite and sandstone cobbles. Fig. 5B shows the net bleaching at the surface (detrapping rate $\times$ exposure time) derived from curve fitting using the equation (1) of Sohbati et al. (2012a), as a function of transport distance.

$$
L=L_{0} e_{186}^{-\frac{184}{\sigma \varphi_{9}} t e^{-\mu x}}
$$

where $\mathrm{L}_{0}$ is the maximum luminescence signal intensity at saturation, $\mathrm{L}$ is the luminescence remaining at depth $\mathrm{x}(\mathrm{mm})$ after an exposure time $\mathrm{t}(\mathrm{s}), \overline{\sigma \varphi_{0}}\left(\mathrm{~s}^{-1}\right)$ is the effective decay rate of the luminescence at the rock surface and $\mu\left(\mathrm{cm}^{-1}\right)$ is the attenuation coefficient as the light penetrates the rock (Sohbati et al., 2012a).

Both of these parameters are proportional to the total exposure time for a given cobble. The data suggest that relatively rapid bleaching occurs in the first $60 \mathrm{~km}$ of transport, irrespective of cobble lithology, and subsequently there is little or undetectable change in luminescence resetting with depth.

Pairs of sandstone cobbles (16XYH-06-S-03 and 16XYH-06-S-04) and granite cobbles (17XYH-06-G-04 and 17XYH-06-G-01) with different sizes from the same sampling site (site II) were selected to compare their signal resetting properties. The a-axis of the larger sandstone cobble is $10 \mathrm{~cm}$ longer than that of the smaller cobble 
(Table 1). For the two granite cobbles, the size difference is less $(4 \mathrm{~cm})$. The signal profiles from exposed upper surfaces show that the larger granite cobble is bleached to a greater depth than the smaller cobble (Fig. 6B), whereas the bleaching depths in the two sandstone cobbles are indistinguishable (Fig. 6A).

\subsection{Differences in luminescence resetting between upper and lower surfaces}

All signal-depth profiles shown in Fig. 4 and Fig. 6 represent the upper exposed surfaces of measured cobbles. To investigate the difference between upper and lower surfaces of the same granite cobbles, profiles from the buried lower surfaces were also measured. For one cobble (16NCH-01-G-01) from site I, the upper and lower surface profiles are indistinguishable (Fig. 7A). For two cobbles (17XYH-06-G-01 and 17XYH-06-G-04) with different diameters from site II and one cobble (17XYH-09-G-02) from site III, the upper surfaces are bleached to greater depths than the buried lower surfaces (Figs. 7B-D). The resetting depths within the upper surfaces of these cobbles are $\sim 8, \sim 5$, and $\sim 8 \mathrm{~mm}$, and within the buried lower surfaces are $\sim 5$, $\sim 3$, and $\sim 6 \mathrm{~mm}$ (samples 17XYH-06-G-01, 17XYH-09-G-02, and 17XYH-06-G-04, respectively). Similar trends are observed in the depths of the inflection points (Fig. 7B-D).

It is expected that bleaching would increase with downstream transport distance of the cobbles, and this is generally supported by our data in Fig. 4. However, clast size also decreases downstream, by selective transport and deposition, or by clast

\section{Discussion} abrasion and attrition (e.g., Paola et al., 1992; Knighton, 1998; Attal and Lave, 2009), which results in a complex behaviour of bleaching trends. Abrasion and attrition of cobble surfaces competes with luminescence resetting and causes the signal-depth profile to shift 'upward' towards the rock surface. If a model was developed that incorporated the luminescence signal, the attrition/abrasion rates, and the transport 
velocities of cobbles, it might be possible to evaluate the potential luminescence signal that should accumulate on a cobble surface, which could be used to quantify the fluvial transport and erosion processes, similar to the approach used with terrestrial cosmogenic nuclides (TCN) (Carretier and Regard, 2011).

Fig. 6 suggests that the larger cobble is more strongly bleached than the smaller one, possibly due to greater abrasion effects in smaller cobbles resulting in their smaller sizes. Another possibility is that larger cobbles would simply be more likely to sometimes not. In a gently sloping section of a river with a low flow velocity, cobble deposits might be transported and rotated less frequently, and abraded less, compared with high-energy upstream sections. This inference is supported by the comparison between the upper and lower surfaces of an individual cobble (Fig. 7). The upper exposed surface of a granite cobble is penetrated by daylight more deeply than its lower buried surface. This indicates longer sunlight exposure durations for upper surfaces than for lower surfaces, in spite of the potentially greater abrasion on the top surface. It also suggests that either cobbles tend to be emplaced with the same surface facing upwards after each transport event (flood), or that the most recent bleaching exposure dominates the penetration depth. The lack of calibration samples restricts the application of quantitative analysis to luminescence-depth profiles to ascertain whether the upper surface profile is in a steady state, and/or to determine the exposure time difference between the two surfaces. However, the observed large variability in the resetting depths between upper and lower profiles across different samples suggests complex transport dynamics.

The presence of such well-bleached profiles in cobble rock surfaces allows us to determine their burial age without any concerns related to incomplete bleaching when the cobbles are reburied. Where multiple cobble lithologies exist at a particular site, it seems better to choose light-coloured cobbles (e.g. granite) rather than opaque dark-coloured cobbles for sample collection. Taking into account the fluvial transport conditions, suitable larger cobbles would be preferable for examination. Upper cobble surfaces should be marked in the field, because these probably provide the most 
suitable material for determining the burial age of deposits in river terraces.

\section{Conclusions}

This study investigated luminescence-depth profiles from modern riverbed cobbles along the course of the Shiyang River in northwest China. Based on our preliminary results, we arrived at the following conclusions.

(i) Light-coloured granite cobbles are bleached to greater depths than dark-coloured sandstone cobbles. This indicates differences in light penetration due to lithological opacity.

(ii) The depth of the inflection points within cobble surfaces increases downstream along the river course, with almost all bleaching occurring over the first $60 \mathrm{~km}$.

(iii) In general, the depth of the inflection point for an individual cobble is greater in its upper surface than its lower surface, possibly due to longer daylight exposure of the top surface after emplacement, and/or preferential orientation at emplacement arising from cobble shape.

(iv) The upper surface of buried granite cobbles may prove to provide preferred material for constraining the timing of burial of clasts in river terraces.

\section{Acknowledgments}

This work was financially supported by the National Natural Science Foundation of China (project no.: 41472161), the State Key Laboratory of Earthquake Dynamics (project no.: LED2013A09) and the Institute of geology, China Earthquake Administration (project no.: IGCEA1417). 
Aitken, M. J., 1985. Thermoluminescence dating. Academic Press, London.

Attal, M., Lave, J., 2009. Pebble abrasion during fluvial transport: Experimental results and implications for the evolution of the sediment load along rivers. J. Geophys. Res. 114, F04023, doi:10.1029/2009JF001328.

Baril, M.R., Huntley, D.J., 2003. Infrared stimulated luminescence and phosphorescence spectra of irradiated feldspars. Journal of Physics: Condensed Matter 15. 8029-8048.

Bøtter-Jensen L., Thomsen, K.J., Jain, M., 2010. Review of optically stimulated luminescence (OSL) instrumental developments for retrospective dosimetry. Radiat. Meas. 45(3-6), 253-257.

Buylaert, J.-P., Vandenberghe, D., Murray, A.S., Huot, S., De Corte, F., Van den haute, P., 2007. Luminescence dating of old (> $70 \mathrm{ka}$ ) Chinese loess: a comparison of single-aliquot OSL and IRSL techniques. Quat. Geochronol. 2, 9-14.

Chapot, M.S., Sohbati, R., Murray, A.S., Pederson, J.L, Rittenour, T., 2012. Constraining the age of rock art by dating a rock-fall event using single-grain and surface dating luminescence techniques. Quat. Geochronol. 13, 18-25.

Carretier, S., Regard, V., 2011. Is it possible to quantify pebble abrasion and velocity in rivers using terrestrial cosmogenic nuclides? J. Geophys. Res. 116, F04003, doi: 10.1029/2011JF001968.

Ding, Y.H., Wang, S.R., 2001. Introduction to Climate, Ecology and Environment in North-west China. China Meteorological Press, Beijing (in Chinese).

Freiesleben, T., Sohbati, R., Murray, A. S., Jain, M., al Khasawneh, S., Hvidt, S., Jakobsen, B., 2015. Mathematical model quantifies multiple daylight exposure and burial events for rock surfaces using luminescence dating. Radiat. Meas. 81, $1-7$.

Gao, H.S., Li, Z.M., Pan, B.T., Liu, F.L., Liu, X.P., 2016. Fluvial response to late Quaternary climate change in the Shiyang River drainage system, western China. 
Geomorphology. 258, 82-92.

Habermann, J., Schilles, T., Kalchgruber, R., Wagner, G.A., 2000. Steps towards surface dating using luminescence. Radiat. Meas. 32(506), 847-851.

Jain, M., Bøtter-Jensen, L., Murray, A. S., Essery, R., 2007. A peak structure in isothermal luminescence signals in quartz: Origin and implications. J. Lum. 127(2), 678-688.

Knighton, D., 1998. Fluvial Forms and Processes - a New Perspective. London, Arnold, 383 pp.

Laskaris, N., Liritzis, I., 2011. A new mathematical approximation of sunlight attenuation in rocks for surface luminescence dating. J. Lum. 131, 1874-1884.

Liritzis, I., Galloway, R.B., 1999. Dating implications from solar bleaching of thermoluminescence of ancient marble. Journal of Radio analytical and Nuclear Chemistry, 241(2), 361-368.

Liritzis, I., Guibert, P., Foti, F., Schvoerer, M., 1996. Solar bleaching of thermoluminescence of calcites. Nucl. Instrum. Meth. 117, 260-268.

Liritzis, I., Guibert, P., Foti, F., Schvoerer, M., 1997. The Temple of Apollo (Delphi) strengthens novel thermoluminescence dating method. Geoarchaeology: An International Journal. 12(5), 479-496.

Paola, C., Parker, G., Seal, R., Sinha, S., Southard, J., Wilcock, R., 1992. Downstream fining by selective deposition in a laboratory flume. Science. 258, 1757-1760.

Polikreti, K., Michael, C.T., Maniatis, Y., 2002. Authenticating marble sculpture with thermoluminescence. Ancient TL. 20, 11-18.

Sohbati, R., Murray, A.S., Jain, M., Buylaert, J.-P., Thomsen, K.J., 2011. Investigating the resetting of OSL signals in rock surfaces. Geochronometria. 38, 249-258.

Sohbati, R., Murray, A.S., Chapot, M.S., Jain, M., Pederson, J., 2012a. Optically stimulated luminescence (OSL) as a chronometer for surface exposure dating. J. Geophys. Res. 117, B09202.

Sohbati, R., Jain, M., Murray, A.S., 2012b. Surface exposure dating of non-terrestrial bodies using optically stimulated luminescence: A new method. Icarus. 221, 
160-166.

Sohbati, R., Murray, A.S., Buylaert, J.-P., Almeida, N.A.C, Cunha, P.P., 2012c. Optically stimulated luminescence dating of quartzite cobbles from the Tapada do Montonho archaeological site. Boreas. 41, 452-462.

Sohbati, R., Murray, A., Jain, M., Thomsen, K., Hong, S.-C., Yi, K., Choi, J.-H., 2013. Na-rich feldspar as a luminescence dosimeter in infrared stimulated luminescence (IRSL) dating. Radiat. Meas. 51-52, 67-82.

Sohbati, R., Murray, A.S., Porat, N., Jain, M., Avner, U., 2015. Age of a prehistoric "Rodedian" cult site constrained by sediment and rock surface luminescence dating techniques. Quat. Geochronol. 30, 90-99.

Vafiadou, A., Murray, A.S., Liritzis, I., 2007. Optically stimulated luminescence (OSL) dating investigations of rock and underlying soil from three case studies. Journal of Archaeological Science. 34, 1659-1669.

Wallinga, J., Bos, A. J. J., Dorenbos, P., Murray, A. S., Schokker, J., 2007. A test case for anomalous fading correction in IRSL dating. Quat. Geochronol. 2, 216-221.

Wallinga, J., Murray, A.S. Wintle, A.G., 2000. The single-aliquot regenerative-dose ( SAR) protocol applied to coarse-grain feldspar. Radiat. Meas. 32, 529-533.

Zhao, H., Li, S.H., 2005. Internal dose rate to K-feldspar grains from radioactive elements other than potassium. Radiat. Meas. 40, 84-93. 


\section{Figure Captions}

Fig. 1 Study area at the northeast margin of the Tibetan Plateau. Samples were collected from the Xiying River, one of the main branches of the Shiyng River (after Gao et al., 2015).

Fig. 2 GPS elevations of 12 sampling sites and the mean grain sizes of boulders/cobbles along the river course. Only samples from three sites (I, II, and III) were analyzed for luminescence behaviour.

Fig. 3 Representative IRSL stimulation curves and dose-response curves (insets) for sandstone (A) and granite (B) cobble samples.

Fig. 4 Comparison of the luminescence signal-depth profiles from the upper exposed surfaces of sandstone (A) and granite (B) cobble samples from sites I, II, and III. Each data point represents the average of $L_{n} / T_{n}$ values measured from three rock slices. The lower photos show the corresponding cobbles for these profiles.

Fig. 5 Depth of the inflection point (A) and net bleaching at the surface (detrapping rate $\times$ exposure time) $(\mathrm{B})$, versus the transport distance from the river source.

Fig. 6 Differences between signal-depth profiles from the upper exposed surfaces of sandstone cobbles (A) and granite cobbles (B) with different diameters from the same sampling site (site II).

Fig. 7 Variations in bleaching depth within the upper (filled circle) and lower (open circle) rock surfaces of each granite cobble from three sampling sites (I, II, and III). Larger (B) and smaller (C) cobbles are both from site II.

\section{Supplementary Figure Caption}

Fig. S1 Views of fluvial landforms and cobbles sampled in this study.

\section{Table Heading}

Table.1 Summary of the size diameters and sampling locations of cobbles analyzed in this study. 
Table.1 Summary of the size diameters and sampling locations of cobbles analyzed in this study.

\begin{tabular}{|c|c|c|c|c|c|}
\hline Sample No & $\begin{array}{c}\text { Cobble size } \\
(\text { length } \times \text { width } \times \text { thickness)* } \\
(\mathrm{cm})\end{array}$ & $\begin{array}{l}\text { Sampling } \\
\text { location }\end{array}$ & Lithology & $\begin{array}{l}\text { Longitude (E) } \\
\text { /latitude (N) }\end{array}$ & $\begin{array}{l}\text { Altitude } \\
\quad(\mathrm{m})\end{array}$ \\
\hline $16 \mathrm{NCH}-01-\mathrm{S}-02$ & $14 \times 10 \times 7$ & Site I & Sandstone & $\begin{array}{ccc}101^{\circ} & 50^{\prime} & 41^{\prime \prime} \\
37^{\circ} & 38^{\prime} & 11^{\prime \prime}\end{array}$ & 3030 \\
\hline 16XYH-06-S-03 & $13 \times 10 \times 6$ & Site II & Sandstone & $\begin{array}{ccc}102^{\circ} & 08^{\prime} & 16^{\prime \prime} \\
37^{\circ} & 52^{\prime} & 59^{\prime \prime}\end{array}$ & 2130 \\
\hline 16XYH-06-S-04 & $23 \times 15 \times 8$ & Site II & Sandstone & $\begin{array}{ccc}102^{\circ} & 08^{\prime} & 16^{\prime \prime} \\
37^{\circ} & 52^{\prime} & 59^{\prime \prime}\end{array}$ & 2130 \\
\hline 16XYH-09-S-03 & $15 \times 10 \times 6$ & & Sandstone & $\begin{array}{ccc}102^{\circ} & 23^{\prime} & 47^{\prime \prime} \\
38^{\circ} & 01^{\prime} & 32^{\prime \prime}\end{array}$ & 1720 \\
\hline $17 \mathrm{NCH}-01-\mathrm{G}-01$ & $22 \times 13 \times 3$ & Site I & Granite & $\begin{array}{ccc}101^{\circ} & 50^{\prime} & 41^{\prime \prime} \\
37^{\circ} & 38^{\prime} & 11^{\prime \prime}\end{array}$ & 3030 \\
\hline 17XYH-06-G-01 & $18 \times 12 \times 7$ & Site II & Granite & $\begin{array}{ccc}102^{\circ} & 08^{\prime} & 16^{\prime \prime} \\
37^{\circ} & 52^{\prime} & 59^{\prime \prime}\end{array}$ & 2130 \\
\hline 17XYH-06-G-04 & $14 \times 10 \times 4$ & Site II & Granite & $\begin{array}{ccc}102^{\circ} & 08^{\prime} & 16^{\prime \prime} \\
37^{\circ} & 52^{\prime} & 59^{\prime \prime}\end{array}$ & 2130 \\
\hline 17XYH-09-G-02 & $16 \times 13 \times 5$ & Site III & Granite & $\begin{array}{ccc}102^{\circ} & 23^{\prime} & 47^{\prime \prime} \\
38^{\circ} & 01^{\prime} & 32^{\prime \prime}\end{array}$ & 1720 \\
\hline
\end{tabular}

* Length represents the long (a-) axis, width the intermediate (b-) axis, and thickness the short (c-) axis of cobbles. 
Fig. 1

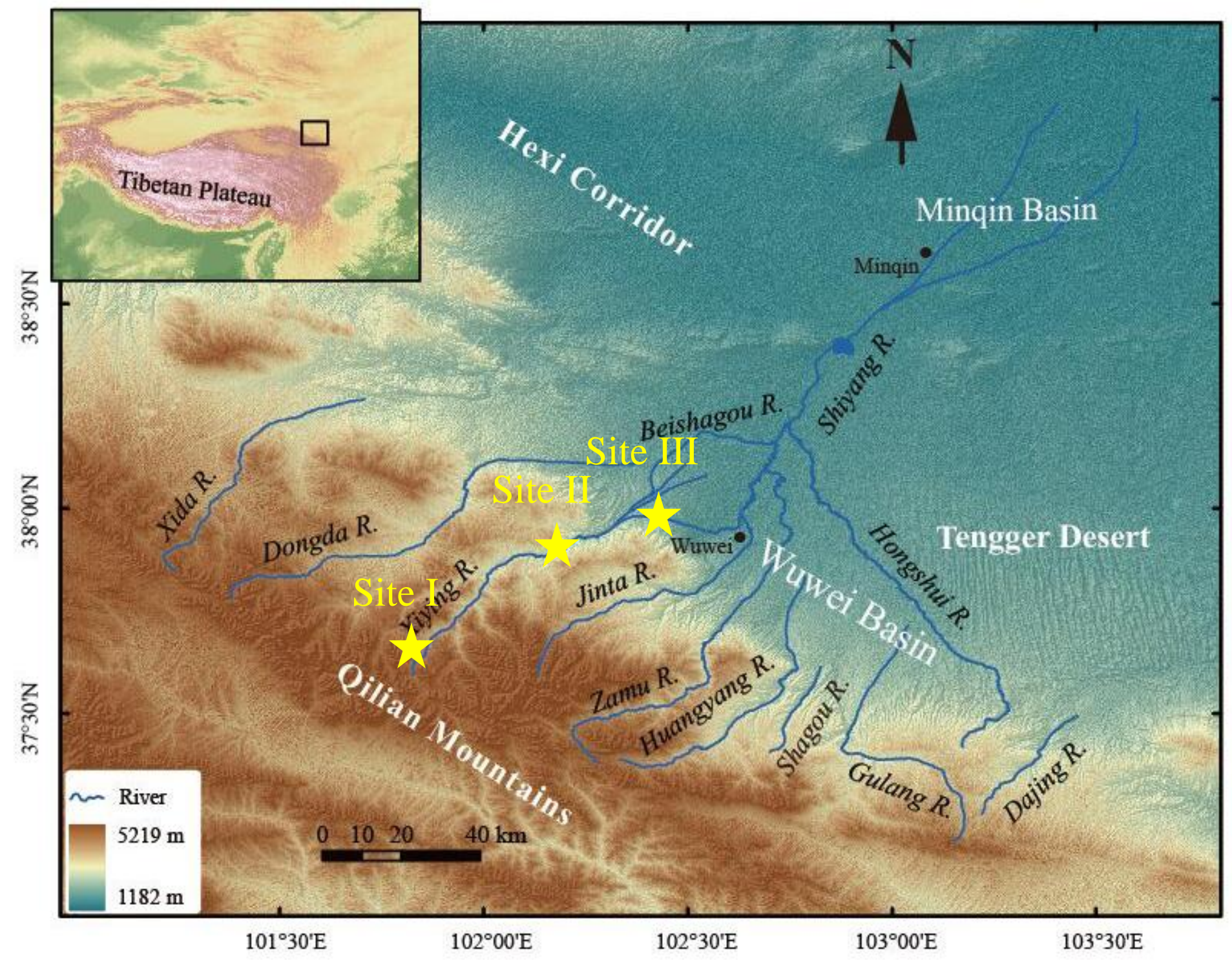


Fig. 2

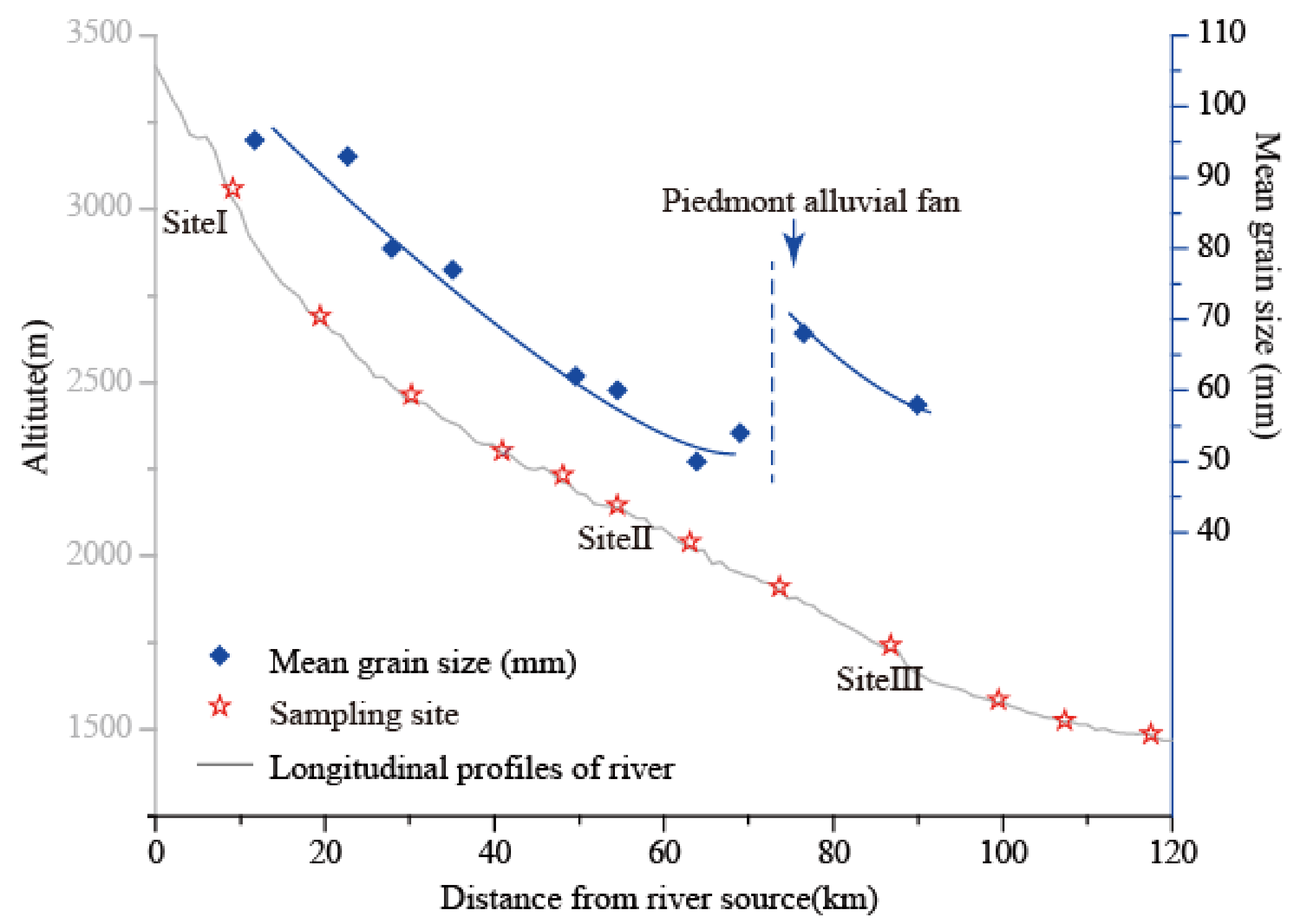


Fig. 3
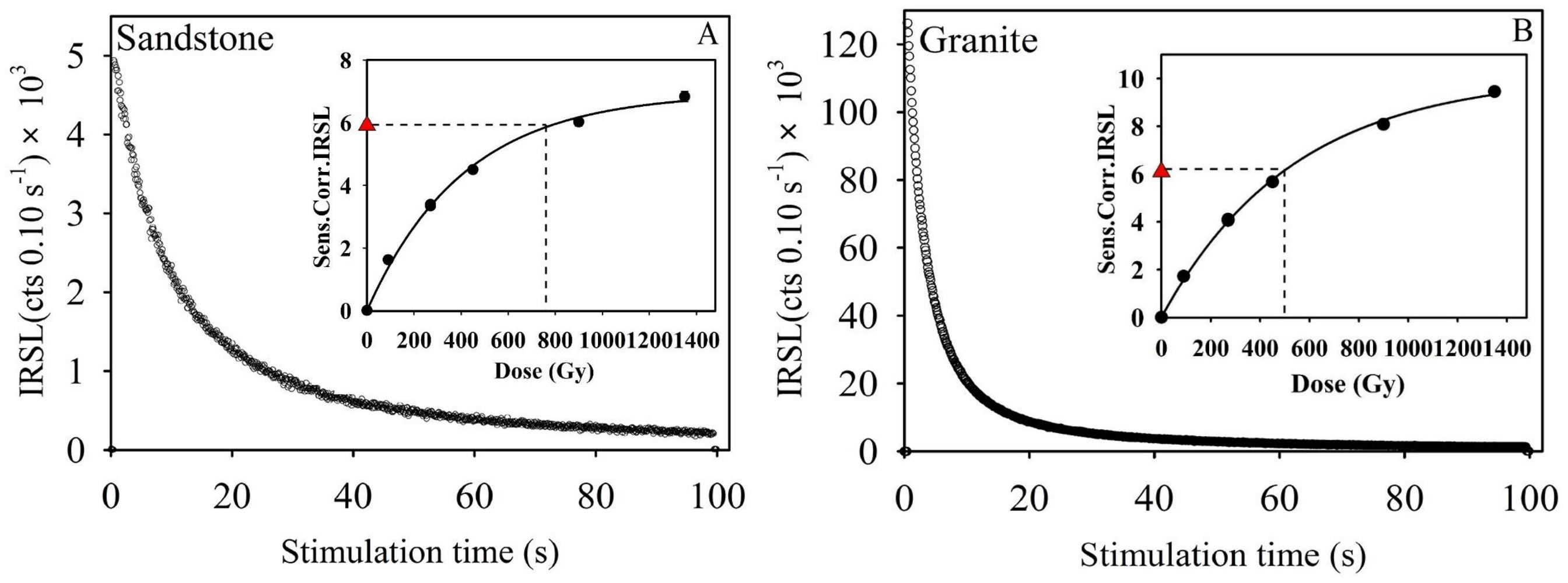
Fig. 4
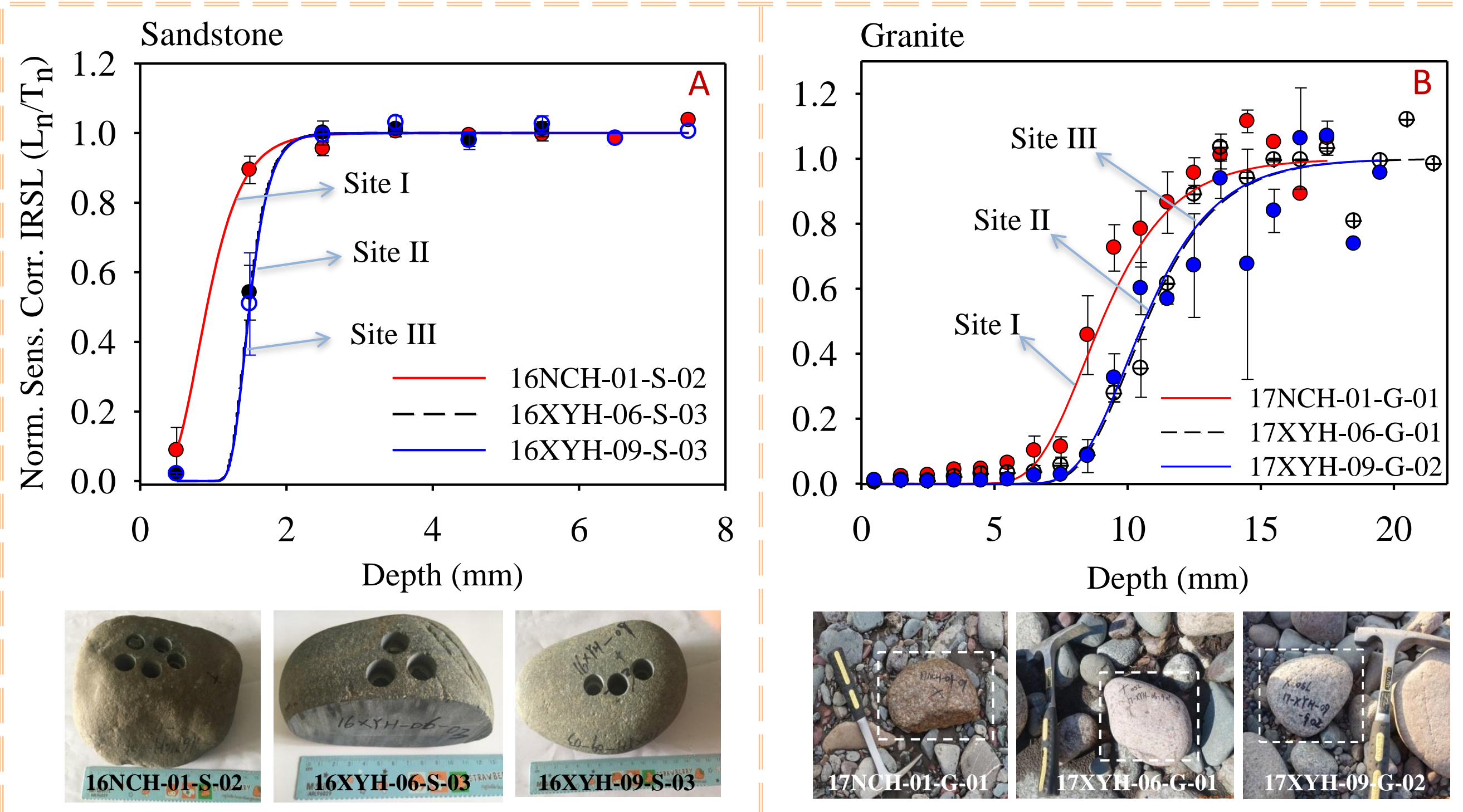
Fig. 5
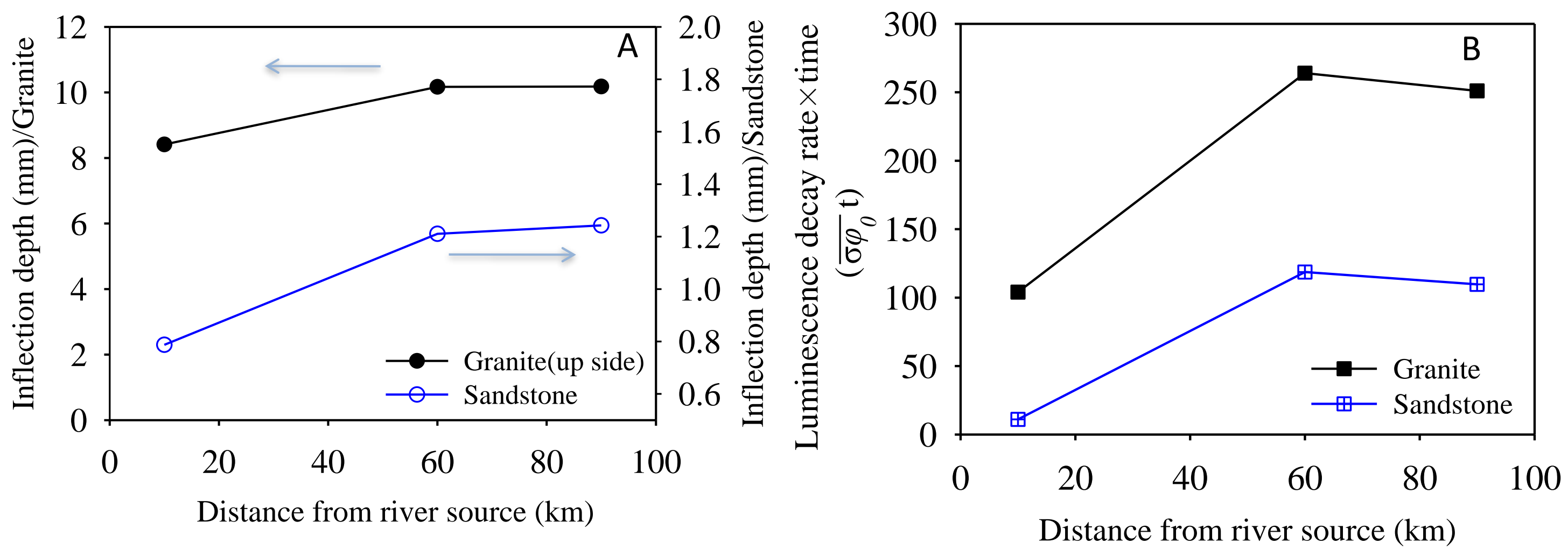
Fig. 6
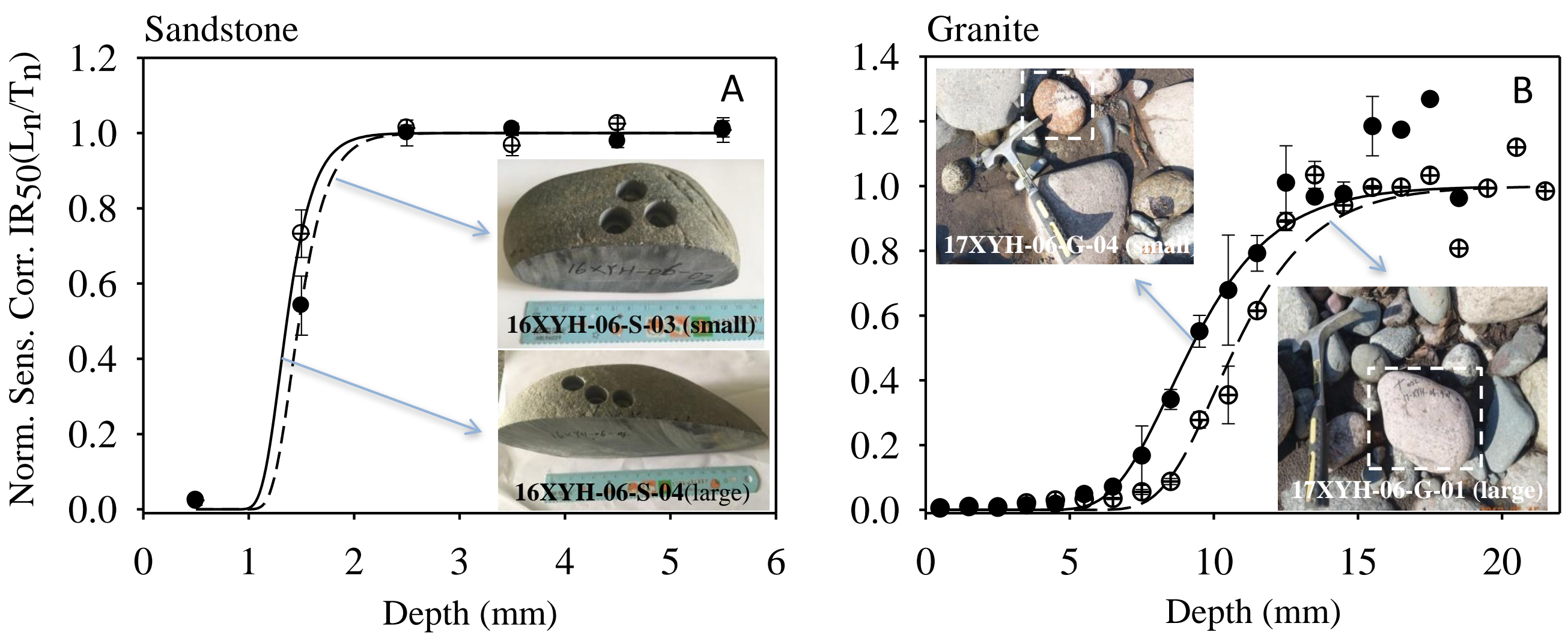
Fig. 7
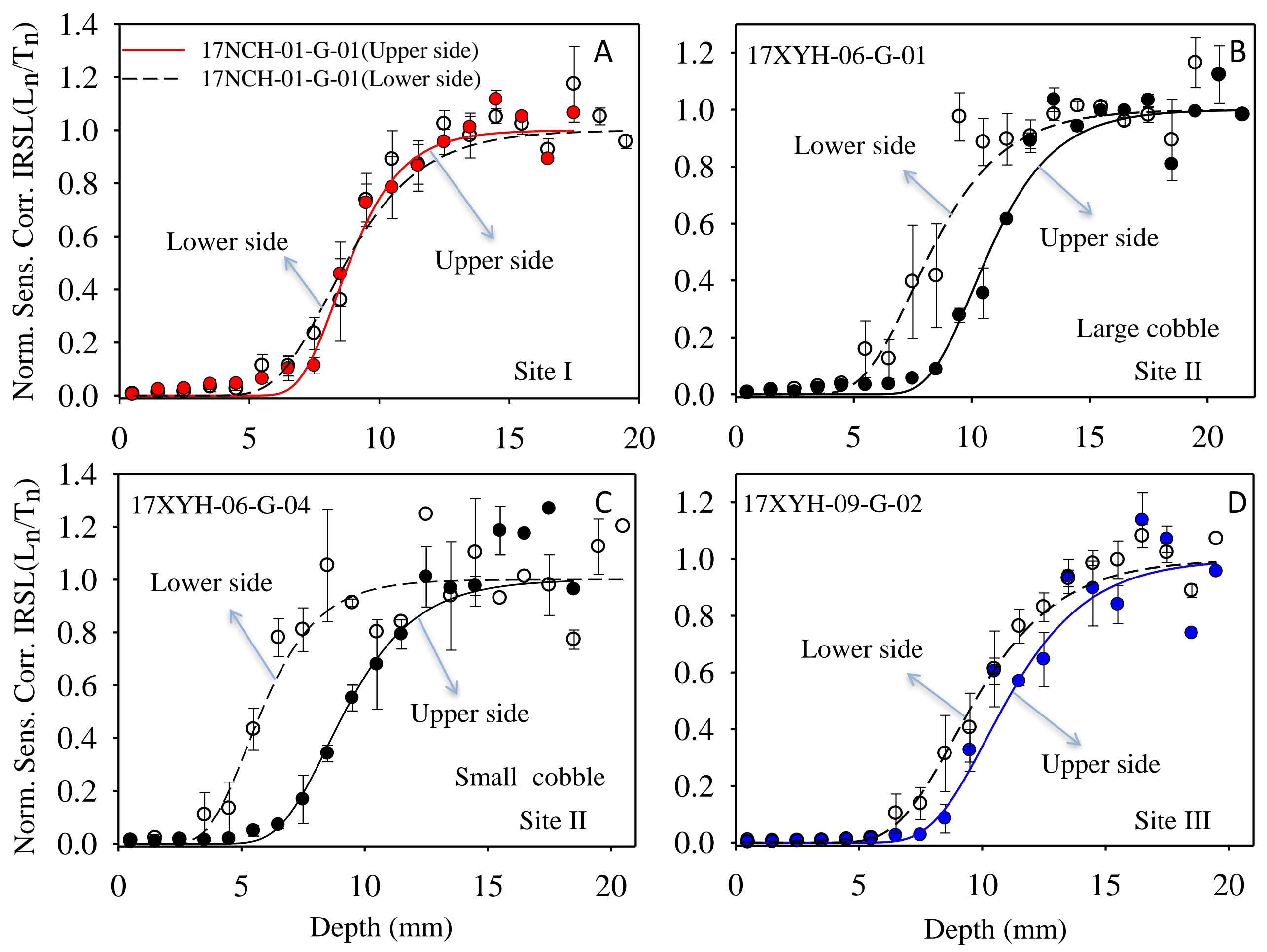
Fig. S1
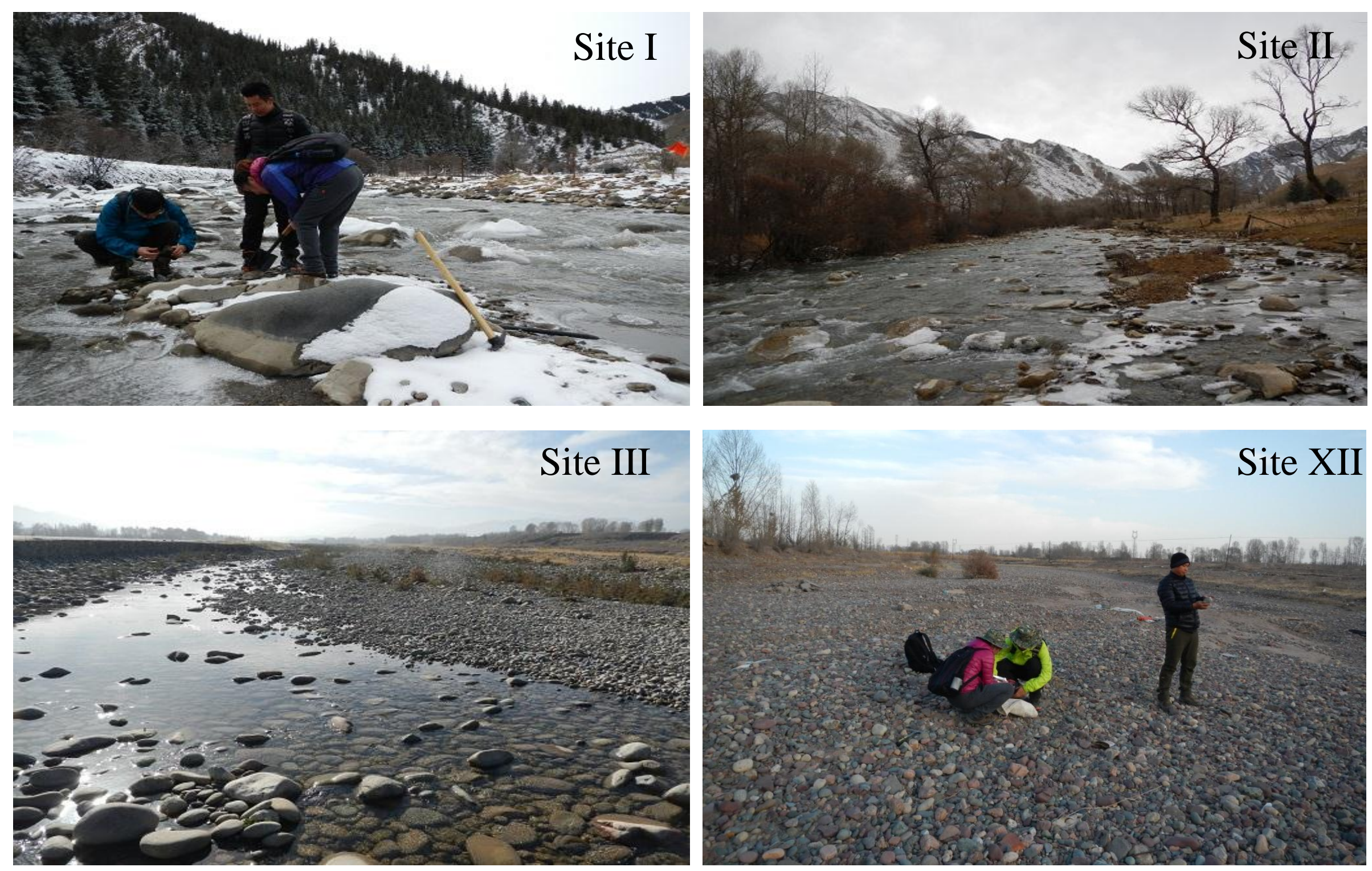


\section{Highlights}

- For series of cobbles (sandstone and granite) taken along a river course, the daylight bleaching depths into cobbles show a downstream increasing trend.

- For a single granite cobble, the upper exposed surface is better bleached than the lower buried surface. 